\begin{tabular}{|l|l|}
\hline & $\begin{array}{l}\text { Jurnal Bimbingan dan Konseling Ar-Rahman } \\
\text { Volume 4, Nomor 2,Tahun } 2018 \\
\text { Tersedia Online: } \text { http://ojs.uniska.ac.id/index.php/BKA } \\
\text { e-ISSN 2477-6300 }\end{array}$ \\
\hline
\end{tabular}

\title{
PEMAHAMAN DIRI SISWA SMP TENTANG MASA PUBERTAS (BALIGH) SEBAGAI FONDASI LAYANAN BIMBINGAN DAN KONSELING
}

\author{
Ani Wardah \\ Program Studi Bimbingan dan Konseling, Fakultas Keguruan dan Ilmu Pendidikan Universitas Islam \\ Kalimantan Muhammad Arsyad Al-Banjari \\ E-mail: aniwardah1412@gmail.com
}

\begin{abstract}
ABSTRAK
Penelitian ini bertujuan untuk mendeskripsikan pemahaman diri siswa SMP tentang masa pubertas/baligh sebagai dasar layanan bimbingan dan konseling. Penelitian ini menggunakan metode kuantitatif dengan pendekatan analisis deskriptif. Populasi penelitian adalah seluruh siswa SMPN 13 Banjarmasin yang berjumlah 607 siswa dengan menggunakan teknik stratifikasi sampling. Jumlah sampel yang diambil 120 siswa yaitu kelas VIII dan IX yaitu yang terdiri dari 60 siswa laki-laki dan 60 siswa perempuan yang terdaftar pada tahun ajaran 2018/2019. Instrumen yang digunakan adalah angket. Tehnik analisis data menggunakan teknik analisa persentase. Hasil penelitian menunjukkan bahwa pemahaman diri siswa SMP Negeri 13 tentang masa pubertas/baligh adalah sebagian besar siswa laki-laki dan siswa perempuan sudah baligh pada rentang usia 11 dan 14 tahun, dan merasa biasa saja terhadap perubahan fisik, psikis, dan sosial emosional. Bagi siswa laki-laki pengalaman mimpi basah (baligh) sebagian besar tertutup kepada orangtua, sebaliknya siswa perempuan sangat terbuka terutama kepada ibu. Sebagian besar yang mengajari tatacara mandi wajib kepada siswa laki-laki adalah guru agama, dan bagi siswa perempuan adalah ibunya. Siswa laki-laki ketika junub lebih banyak tidak mengerjakan mandi wajib, sebaliknya siswa perempuan selalu mengerjakan mandi wajib selesai menstruasi. Berdasarkan temuan hasil penelitian tersebut sebagai dasar pelayanan Bimbingan dan Konseling.
\end{abstract}

Kata Kunci: Pemahaman Diri; Masa Pubertas; Bimbingan Dan Konseling

\begin{abstract}
This study aims to describe the self-understanding of middle school students about puberty / baligh as a basis for counseling and guidance services. This study uses a quantitative method with a descriptive analysis approach. The study population was all students of SMPN 13 Banjarmasin, totaling 607 students using sampling stratification techniques. The number of samples taken by 120 students is class VIII and IX, which consists of 60 male students and 60 female students enrolled in the 2018/2019 school year. The instrument used was a questionnaire. Data analysis techniques use percentage analysis techniques. The results showed that the selfesteem of SMP Negeri 13 students about puberty / baligh was that most male and female students were already high in the ages of 11 and 14 years, and felt normal towards physical, psychological, and social emotional changes. For male students the experience of baligh dreams is mostly closed to parents, whereas female students are very open especially to mothers. Most of those who teach mandatory bathing procedures for male students are religious teachers, and for female students are their mothers. Male students when Junub did not do mandatory bathing, on the other hand female students always did bathing and had to finish menstruation. Based on the findings of the research as a basis for Guidance and Counseling services.
\end{abstract}

Keywords: Self-Understanding; Puberty; Guidance and Counseling

Dipublikasikan Oleh :

UPT Publikasi dan Pengelolaan Jurnal

Universitas Islam Kalimantan Muhammad Arsyad Al-Banjari Banjarmasin 


\section{PENDAHULUAN}

Siswa Sekolah Menengah Pertama (SMP) dalam perkembangannya ada pada masa remaja. Remaja adalah mereka yang berada pada rentang usia 13 tahun sampai 18 tahun (Hurlock, 2003). Menurut Papalia et.al (2008), masa remaja dimulai pada usia 11 atau 12 sampai remaja akhir atau awal dua puluhan.

Masa remaja merupakan masa perkembangan transisi antara masa anak dan masa dewasa yang mencakup perubahan biologis, kognitif dan sosial emosial (Santrock, 2003). Menurut Hurlock (1980) istilah remaja berasal dari bahasa latin adolescense yang berarti "tumbuh" atau "tumbuh menjadi dewasa". Istilah adolescence memiliki arti yang luas, mencakup kematangan mental, emosional, sosial dan fisik.

Remaja selama menjalani masa pubertas akan mengalami banyak perubahan fisik dan psikologis yang sifatnya sangat cepat. Pada anak laki-laki, perubahan seks primer, ditandai dengan mimpi basah. sedangkan perubahan sekunder berupa suara mulai berubah, tumbuh rambut di daerah ketiak, kumis, jenggot, di sekitar alat kelamin. Perubahan seks primer pada anak perempuan ditandai dengan menstruasi pertama kali (menarche) dan biasanya diikuti dengan perubahan organ seksual sekunder yaitu memiliki payudara dan pinggul yang membesar (Soetjingsih, 2004). Perubahan mental ditandai dengan ketertarikan kepada lawan jenis.

Menurut Daradjat (1994), istilah remaja atau kata yang berarti remaja tidak ada dalam Islam. Dalam Al Qur'an terdapat kata baligh yang menunjukkan bahwa seseorang tidak kanak-kanak lagi, disebutkan dalam surah An Nur ayat 59. Remaja yang ditandai dengan kematangan seksual (dalam Islam dikenal dengan baligh) tidak hanya terjadi perubahan fisik, psikis, dan perilaku sosial.

"Baligh" berasal dari bahasa arab dari kata bulugh yang memiliki arti 'sampai', maksudnya telah sampai usia seseorang pada tahap kedewasaan. Sedangkan menurut makna terminologis, al-bulugh adalah berakhirnya masa kanak-kanak (dalam fikih Islam). Secara sosial, seseorang yang sudah baligh bertanggung jawab penuh terhadap perbuatan (baikburuk) yang ia lakukan sehingga ia memiliki tanggung jawab moral. Secara agama baligh merupakan batas bagi seseorang untuk dibebani kewajiban dan tanggung jawab terhadap seluruh hukum agama. Tanda-Tanda Baligh menurut Islam adalah:

1. Sempurnanya umur

Sempurnanya umur seorang anak laki-laki ialah ketika sudah memasuki umur minimal 15 tahun dan sempurnanya umur seorang anak perempuan minimal 9 tahun.

2. Keluarnya air mani
Tanda seorang anak laki-laki sudah baligh ialah ditandai dengan keluarnya sperma pertama, biasanya lewat bermimpi merasakan kepuasan seksual (Ahmadi, 2005).

\section{Haid atau Menstruasi}

Tanda seorang anak perempuan sudah baligh ialah saat seorang anak perempuan mengalami proses menstruasi pertama kali (Menarche) (Ahmadi, 2005). Seorang perempuan dikatakan baligh ketika tiba menstruasi, yang berarti sudah memiliki kewajiban terhadap syariat agama (Yusuf dkk, 2014)

Kesimpulan bahwa anak laki-laki dan anak perempuan yang telah mengalami salah satu dari tanda- tanda baligh tersebut, maka mereka sudah baligh (sudah dewasa). Seseorang muslim yang sudah baligh, berlaku baginya seluruh ketentuan hukum Islam yaitu menjalankan semua perintah dan menjauhi semua larangan Allah SWT.

Berdasarkan hasil observasi dan wawancara peneliti, yang dilakukan bulan Nopember 2018 kepada siswa SMP, ditemukan beberapa siswa perempuan dan siswa laki-laki mengalami perubahan fisik yang sangat pesat, dan ada beberapa orang siswa perempuan dan siswa laki-laki yang lambat mengalami perubahan fisik yaitu bentuk badan mereka masih seperti anakanak.

Berdasarkan hasil wawancara kepada siswa perempuan, A namanya disamarkan, si A sudah mengalami menarche sejak usia 11 tahun atau sejak kelas $5 \mathrm{SD}$, dan B siswa kelas 2 SMP belum mengalami menarche. dan $\mathrm{C}$ siswa laki-laki mengalami mimpi basah sejak usia 12 tahun (kelas 6 SD). Demikian juga perasaan terhadap lawan jenis, ada beberapa siswa yang saling tertarik menjalin hubungan (pacaran) rentangan usia mereka 11 tahun 13 tahun. Berdasarkan hasil studi pendahuluan peneliti tertarik untuk melakukan penelitian tentang pemahaman diri siswa SMP tentang masa pubertas/baligh sebagai dasar layanan bimbingan dan konseling.

\section{METODE}

Tujuan penelitian adalah untuk mendapatkan gambaran empirik pemahaman diri siswa SMP tentang masa pubertas/baligh sebagai dasar layanan bimbingan dan konseling. Penelitian dilakukan pada bulan November 2018 - Desember 2018 di SMP Negeri 13 Banjarmasin.

Metode penelitian yang digunakan adalah metode kuantitatif dengan pendekatan analisis deskriptif dengan jenis penelitian survei. Populasi penelitian ini adalah siswa SMP Negeri 13 Banjarmasin dengan jumlah keseluruhan 607 siswa dengan menggunakan sampel teknik stratifikasi sampling. Teknik stratifikasi sampling yaitu terdiri dari beberapa lapisan atau kelompok individual 
dengan karakteristik berbeda (Sukardi, 2017:60). Di sekolah, misalnya ada kelas VII, kelas VIII, dan kelas IX. Mereka juga dapat dibedakan menurut jenis kelamin menjadi kelompok responden laki-laki dan kelompok perempuan.

Sampel dalam penelitian ini berjumlah 120 siswa yaitu kelas VIII dan IX yaitu yang terdiri dari 60 siswa laki-laki dan 60 siswa perempuan yang terdaftar pada tahun ajaran 2018/2019. Instrumen yang digunakan adalah angket. Tehnik analisis data yang digunakan adalah teknik analisa persentase. Menurut Yusuf, A.M. (2005:115) setelah semua jawaban terkumpul, selanjutnya ditabulasikan hasil jawaban dengan rumusan sebagai berikut:
$\mathrm{P}=\frac{f}{n} \times 100 \%$

Keterangan:

$\mathrm{P}=$ Tingkat persentasi jawaban

$\mathrm{f}=$ Frekuensi jawaban

$\mathrm{n}=$ Jumlah responden.

\section{HASIL DAN PEMBAHASAN}

Hasil penelitian menunjukkan bahwa pemahaman diri siswa tentang masa pubertas/baligh dapat dilihat tabel berikut ini, yang didistribusikan menjadi frekuensi yang sederhana yaitu:

Tabel 1 Karakteristik Responden Berdasarkan Umur Baligh

\begin{tabular}{ccccc}
\hline Variabel & \multicolumn{2}{c}{ Laki-laki } & \multicolumn{2}{c}{ Perempuan } \\
\cline { 2 - 5 } & $\mathrm{F}$ & $\%$ & $\mathrm{~F}$ & $\%$ \\
\hline Umur & & & 2 & $3,3 \%$ \\
10 tahun & - & - & 11 & $18,3 \%$ \\
11 tahun & 6 & $10 \%$ & 20 & $33,3 \%$ \\
12 tahun & 21 & $35 \%$ & 23 & $38 \%$ \\
13 tahun & 25 & $41 \%$ & 2 & $3,3 \%$ \\
14 tahun & 7 & $11,7 \%$ & 58 & $96,5 \%$ \\
Total baligh & 59 & $98,4 \%$ & 2 & $3,3 \%$ \\
Belum Baligh & 1 & $1,7 \%$ & 60 & $100 \%$ \\
Total & 60 & $100 \%$ & & \\
\hline
\end{tabular}

Tabel 2. Perasaan Responden Berdasarkan Perubahan Fisik Masa Pubertas

\begin{tabular}{cccccc}
\hline No & Variabel & \multicolumn{2}{c}{ Laki-laki } & \multicolumn{2}{c}{ Perempuan } \\
\cline { 3 - 6 } & & $\mathrm{F}$ & $\%$ & $\mathrm{~F}$ & $\%$ \\
\hline 1. & Senang & 10 & $16,7 \%$ & 7 & $11,7 \%$ \\
2 & Cemas & 2 & $3,3 \%$ & 2 & $3,3 \%$ \\
3 & Gelisah & 1 & $1,7 \%$ & 3 & $5 \%$ \\
4 & Biasa saja & 47 & $78,3 \%$ & 48 & $80 \%$ \\
& Total & 60 & $100 \%$ & 60 & $100 \%$ \\
\hline
\end{tabular}

Tabel 3. Perasaan Responden Masa Pubertas Kepada Lawan Jenis

\begin{tabular}{cccccc}
\hline \multirow{2}{*}{ No } & Variabel & \multicolumn{2}{c}{ Laki-laki } & \multicolumn{2}{c}{ Perempuan } \\
\cline { 3 - 6 } & & F & $\%$ & F & $\%$ \\
\hline 1. & Menyukai & 39 & $65 \%$ & 47 & $78 \%$ \\
2 & Saling Menyukai & 8 & $13,3 \%$ & 2 & $3,3 \%$ \\
3 & Tidak Menyukai & 13 & $21,7 \%$ & 11 & $18,3 \%$ \\
4 & Biasa saja & - & - & - & - \\
& Total & 60 & $100 \%$ & 60 & $100 \%$ \\
\hline
\end{tabular}

Tabel 4. Perasaan Responden Setelah Baligh

\begin{tabular}{clcccc}
\hline \multirow{2}{*}{ No } & Variabel & \multicolumn{2}{c}{ Laki-laki } & \multicolumn{2}{c}{ Perempuan } \\
\cline { 2 - 6 } & & F & $\%$ & F & $\%$ \\
\hline 1. & Senang & 4 & $6,7 \%$ & 7 & $11,7 \%$ \\
& Cemas & 1 & $1,7 \%$ & 1 & $1,7 \%$ \\
& Gelisah & 3 & $5 \%$ & 3 & $5 \%$ \\
& Biasa saja & 51 & $85 \%$ & 46 & $76,7 \%$ \\
& Total baligh & 59 & $98,4 \%$ & 58 & $96,8 \%$ \\
2 & Belum baligh & 1 & $1,7 \%$ & 2 & $3,3 \%$ \\
& Total & 60 & $100 \%$ & 60 & $100 \%$ \\
\hline
\end{tabular}

Dipublikasikan Oleh :

UPT Publikasi dan Pengelolaan Jurnal

Universitas Islam Kalimantan Muhammad Arsyad Al-Banjari Banjarmasin 
Ani Wardah

Jurnal Bimbingan dan Konseling Ar-Rahman

Volume 4, Nomor 2, Tahun 2018

e-ISSN 2477-6300

Tabel 5. Responden Setelah Baligh menceritakan ke

\begin{tabular}{cccccc}
\hline \multirow{2}{*}{ No } & Variabel & \multicolumn{2}{c}{ Laki-laki } & \multicolumn{2}{c}{ Perempuan } \\
\cline { 3 - 6 } & & $\mathrm{F}$ & $\%$ & $\mathrm{~F}$ & $\%$ \\
\hline 1. & Teman & 11 & $18,3 \%$ & & -- \\
& Ayah & 4 & $6,7 \%$ & & -- \\
& Ibu & 7 & $11,7 \%$ & 57 & $95 \%$ \\
& Tidak Menceritakan & 37 & $61,7 \%$ & 1 & $1,7 \%$ \\
& Total baligh & 59 & $98,4 \%$ & 58 & $96,7 \%$ \\
2 & Belum Baligh & 1 & $1,7 \%$ & 2 & $3.3 \%$ \\
& Total & 60 & $100 \%$ & 60 & $100 \%$ \\
\hline
\end{tabular}

Tabel 6. Responden Setelah Baligh Wajib Mandi Junub

\begin{tabular}{|c|c|c|c|c|c|}
\hline \multirow[t]{2}{*}{ No } & \multirow[t]{2}{*}{ Variabel } & \multicolumn{2}{|c|}{ Laki-laki } & \multicolumn{2}{|c|}{ Perempuan } \\
\hline & & $\mathrm{F}$ & $\%$ & $\mathrm{~F}$ & $\%$ \\
\hline 1. & $\begin{array}{l}\text { Tidak mengetahui } \\
\text { bahwa semua } \\
\text { orang Islam } \\
\text { hukumnya wajib }\end{array}$ & 2 & $3.3 \%$ & 2 & $3,3 \%$ \\
\hline 2 & $\begin{array}{l}\text { Mengetahui tetapi } \\
\text { tidak mengerjakan }\end{array}$ & 30 & $50 \%$ & 14 & $23,3 \%$ \\
\hline 3 & $\begin{array}{l}\text { Mengetahui tetapi } \\
\text { kadang-kadang } \\
\text { mengerjakan }\end{array}$ & - & - & - & - \\
\hline 4 & $\begin{array}{l}\text { Mengetahui dan } \\
\text { selalu } \\
\text { mengerjakan }\end{array}$ & 27 & $45 \%$ & 42 & $70 \%$ \\
\hline & Total baligh & 59 & $98,4 \%$ & 58 & $96,7 \%$ \\
\hline & Belum baligh & 1 & $1,7 \%$ & 2 & $3.3 \%$ \\
\hline & Total & 60 & $100 \%$ & 60 & $100 \%$ \\
\hline
\end{tabular}

Tabel 7 Mengajarkan Responden Tata Cara Mandi Wajib

\begin{tabular}{ccccc}
\hline Variabel & \multicolumn{2}{c}{ Laki-laki } & \multicolumn{2}{c}{ Perempuan } \\
\cline { 2 - 5 } & $\mathrm{F}$ & $\%$ & $\mathrm{~F}$ & $\%$ \\
\hline Ayah & 9 & $15 \%$ & - & \\
\hline Ibu & 7 & $11,7 \%$ & 50 & $83,3 \%$ \\
\hline Guru Agama & 38 & $63,3 \%$ & 8 & $13,3 \%$ \\
\hline $\begin{array}{c}\text { Selain yang } \\
\text { disebutkan }\end{array}$ & 6 & $10 \%$ & 2 & $3,3 \%$ \\
\hline Total & 60 & $100 \%$ & 60 & $100 \%$ \\
\hline
\end{tabular}

Berdasarkan tabel 1 dapat diketahui bahwa sebagian besar pada usia 12 tahun ada $21(35 \%)$ usia 13 tahun ada $25(41 \%)$ responden laki-laki sudah mengalami baligh (mimpi basah). Sebagian besar responden perempuan telah mengalami baligh (menarche) pada usia 12 tahun ada $20(33,3 \%)$ dan pada usia 13 tahun ada 23 (38\%). Responden laki-laki sebagian besar ada 59 (98,4\%) sudah baligh (mengalami mimpi basah), dan responden perempuan sudah mengalami baligh (menarche) sebesar ada 58 $(96,5 \%)$ sudah. Lebih lanjut, Tabel 2 menunjukkan bahwa perasaan responden berdasarkan perubahan fisik pada masa pubertas dari 60 responden laki-laki yang telah menjawab biasa saja ada $47(78,3 \%)$, dan $48(80 \%)$ dari 60 responden perempuan.
Berikutnya melalui Tabel 3 dapat diketahui perasaan responden pada masa pubertas kepada lawan jenis menjawab menyukai lawan jenis ada 39 (65\%) dari 60 responden laki-laki, dan ada 47 (78\%) dari 60 responden perempuan. Tabel 4 menunjukkan bahwa perasaan responden setelah baligh menjawab merasa biasa saja ada $51(85 \%)$ dari 60 responden laki-laki, dan ada $46(76,7 \%)$ dari 60 responden perempuan. Kemudian Tabel 5 menunjukkan bahwa responden setelah baligh menceritakan menjawab tidak menceritakan ada $37(61,7 \%)$ dari 60 responden lakilaki, dan menjawab menceritakan ke ibu ada 57 (95\%) dari 60 responden perempuan.

Selanjutnya berdasarkan tabel 6 dapat diketahui bahwa responden setelah baligh yaitu

Dipublikasikan Oleh :

UPT Publikasi dan Pengelolaan Jurnal 
mengalami mimpi basah bagi responden laki-laki menjawab mengetahui wajib mandi junub tetapi tidak mengerjakan ada $30(50 \%)$ dari 60 responden lakilaki. Yang menjawab mengetahui dan selalu mengerjakan ada $42(70 \%)$ dari responden perempuan. Data terakhir adalah Tabel 7 yang menunjukkan bahwa orang yang mengajarkan responden tata cara mandi junub/wajib yang menjawab guru agama ada 38 (63\%) dari 60 responden laki-laki. Menjawab ibu ada $50(83,3 \%)$ dari 60 responden perempuan.

\section{Karakteristik Responden Berdasarkan Umur Baligh}

Hasil penelitian menunjukkan bahwa sebagian besar siswa laki-laki SMP Negeri 13 baligh atau sudah mengalami mimpi basah pada usia 12 dan 13. Sebagian besar siswa perempuan sudah baligh (menarche) pada usia 12 tahun 13 tahun. Siswa lakilaki sudah baligh (mengalami mimpi basah) sebagian besar ada dimulai pada usia 11 tahun, sedangkan siswa perempuan mulai baligh pada usia 10 tahun. Hal ini menggambarkan bawah siswa perempuan lebih dulu baligh dari pada siswa laki-laki. Juga menunjukkan bahwa sebagian besar siswa SMP Negeri 13 baik siswa laki-laki dan siswa perempuan sudah dewasa, dan sudah berlaku hukum agama Islam terhadap mereka. Sesuai dengan ajaran Islam bahwa tanda-tanda baligh berada pada usia 15 tahun atau apabila seseorang sudah mensturasi bagi perempuan dan mimpi basah bagi laki-laki.

2. Perasaan Siswa SMP Negeri 13 Banjarmasin berdasarkan perubahan fisik pada masa Pubertas/baligh.

Perasaan siswa laki-laki dan siswa perempuan SMP Negeri 13 Banjarmasin terhadap perubahan fisik yang mereka alami merasa biasa saja. Ini artinya bahwa baik siswa laki-laki dan siswa perempuan yang berada pada masa pubertas (baligh) memiliki perasaan yang baik dan biasa saja terhadap perubahan fisik yang sangat pesat. Hal ini didukung oleh hasil penelitian Juliana dkk (2014) bahwa siswa laki-laki dan siswa perempuan memiliki penilaian yang baik terhadap perubahan fisik mereka.

3. Perasaan kepada lawan jenis Siswa SMP Negeri 13 Banjarmasin pada masa Pubertas/baligh

Perasaan siswa laki-laki kepada lawan jenis pada masa pubertas yaitu sebagian besar sudah menyukai/merasa tertarik kepada siswa perempuan. Demikian juga siswa perempuan sebagian besar sudah merasa tertarik dan menyukai lawan jenis (siswa lakilaki). Hal ini menggambarkan bahwa baik siswa lakilaki dan siswa perempuan sudah dewasa dan sudah merasa tertarik dengan lawan jenis. Hal ini sesuai dengan perubahan-perubahan dengan perkembangan karakteristik seksual menurut Zigler dan Svenson (dalam Desmita, 2008).

\section{Perasaan Siswa SMP Negeri 13 Banjarmasin setelah Baligh \\ Perasaan siswa laki-laki setelah mengalami} mimpi basah (baligh) mereka merasa sebagian besar merasa biasa saja. Demikian juga yang dialami siswa perempuan setelah mengalami menarche (haid pertama) mereka sebagian besar merasa biasa saja. Hal ini bertentangan dengan hasil penelitian Bharatwaj, dkk (2014) menyatakan bahwa dari 101 responden remaja putri, sekitar $49 \%$ merasa panik dan $50.49 \%$ merasa buruk pada saat menghadapi menarche. Menurut Kartono (2006) gejala psikologis dari Menarche diantaranya kecemasan dan ketakutan yang kuat oleh keinginan untuk menolak proses dari menarche.

5. Siswa SMP Negeri 13 Banjarmasin setelah Baligh menceritakan ke seseorang

Siswa laki-laki setelah mengalami mimpi basah (baligh) sebagian besar mereka tidak menceritakan kepada siapapun. Berbeda dengan siswa perempuan setelah mengalami menarche (haid pertama) sebagian besar mereka menceritakan ke pada ibu. Hasil penelitian ini menunjukkan bahwa siswa perempuan lebih terbuka kepada ibu. Hal yang berlawanan bawah siswa laki-laki lebih tertutup terutama kepada orangtua. Pendapat Muriyana (2008) orangtua terutama ibu harus memberikan penjelasan tentang menstruasi pertama kepada anak perempuannya, agar anak lebih mengerti dan siap menghadapi menstruasi pertama.

6. Siswa SMP Negeri 13 Banjarmasin setelah mimpi basah bagi siswa laki-laki dan setelah menarche bagi siswa perempuan Wajib Mandi Junub.

Siswa laki-laki setelah mengalami mimpi basah atau junub mereka sebagian besar mengetahui bahwa semua orang Islam wajib mandi junub tetapi mereka tidak mengerjakan mandi junub. Berbeda dengan siswa perempuan setelah selesai haid mereka sebagian besar mengetahui bahwa semua orang Islam wajib mandi junub dan mereka selalu mengerjakan mandi junub. Hal ini sesuai dengan pendapat (Yusuf $\mathrm{dkk}$, 2014) Seorang perempuan dikatakan baligh ketika tiba menstruasi, yang berarti sudah memiliki kewajiban terhadap syariat agama.

Islam sangat memperhatikan remaja, ada halhal yang boleh dilakukan dan tidak, misalnya menjalankan perintah shalat, tidur terpisah dengan orangtua, meminta izin kalau masuk ke kamar orang tua, menjaga pergaulan bebas laki-laki dan perempuan dan lain sebagainya (Jannah, 2016).

7. Mengajari Siswa SMP Negeri 13 Banjarmasin tentang tata cara mandi junub

Orang yang mengajari siswa laki-laki tentang tata cara mandi junub/wajib sebagian besar adalah guru agama. Berbeda dengan siswa perempuan sebagian besar yang mengajari tata cara mandi junub adalah ibu. Hal ini menunjukkan bahwa siswa 
Ani Wardah

Jurnal Bimbingan dan Konseling Ar-Rahman

Volume 4, Nomor 2, Tahun 2018

e-ISSN 2477-6300

perempuan lebih terbuka kepada orangtua terutama dengan ibu. Hal ini sesuai dengan hasil penelitian Hidayah (2018) bahwa terdapat hubungan positif yang signifikan antara kelekatan aman ibu dan anak dengan kesiapan menghadapi menstruasi pertama.

\section{PENUTUP}

Hasil penelitian dapat disimpulkan bahwa pemahaman diri siswa SMP Negeri 13 Banjarmasin tentang masa pubertas/baligh adalah sebagian besar siswa laki-laki dan siswa perempuan sudah baligh pada rentang usia 11 dan 14 tahun, dan mereka merasa biasa saja terhadap perubahan fisik, psikis, dan sosial emosional. Bagi siswa laki-laki pengalaman pertama mimpi basah (baligh) sebagian besar tertutup terutama kepada orangtua, sebaliknya siswa perempuan sangat terbuka kepada ibu. Sebagian besar yang mengajari tatacara mandi wajib kepada siswa laki-laki adalah guru agama, berbeda yang mengajari siswa perempuan adalah ibunya. Siswa laki-laki ketika junub lebih banyak tidak mengerjakan mandi wajib, sebaliknya siswa perempuan selalu mengerjakan mandi wajib selesai menstruasi (haid). Saran berdasarkan temuan hasil penelitian tersebut dijadikan dasar pelayanan Bimbingan dan Konseling.

\section{REFERENSI}

Ahmadi, A. \& Sholeh, M. (2005). Psikologi Perkembangan, Jakarta: PT Rineka Cipta.

Bharatwaj, R.S., Vijaya, K., \& Sindu, T. (2014). Psychosocial Impact Related to Physiological Changes Preceding at and following menarche among adolescent girls. International Journal of Clinical Surgical Advances. 2 (1). 42-53.

Desmita. (2008). Psikologi Perkembangan, Universitas Padjadjaran.

Muriyana, S. D. (2008). Studi kualitatif tentang Kesiapan Remaja Putri Sekolah Dasar dalam Menghadapi Menarche pada Usia 10-12 tahun. Skripsi tidak diterbitkan. Universitas Muhammadiyah Semarang.

Hidayah, N. \& Adisucipto. (2018). Kesiapan Menghadapi Menarceh Pada Remaja Putri Prapubertas Ditinjau dari Kelekatan Aman anak dan Ibu. Jurnal Ilmiah Psikologi. 5 (1)

Hurlock, E. B. (2003). Psikologi Perkembangan Suatu Pendekatan Sepanjang Rentang Kehidupan (Terjemahan oleh Istiwidayanti dan Soedjarwo) Jakarta Erlangga.

Kartono, K. (2006). Psikologi Wanita Dewasa. Bandung: Mandiri Maju.

Jannah, M. (2016). Remaja dan Tugas-Tugas Perkembangannya dalam Islam. Jurnal Psikoislamedia 1 (1).

Juliana, Iberahim., I. \& Sano. A., (2014). Konsep Diri Remaja pada Masa Pubertas dan Implikasinya terhadap Layanan Bimbingan dan Konseling. Jurnal Konseling dan Pendidikan. 2 (1). 1-7.

Santrock, John W. (2003). Adolesence: Perkembangan Remaja. Jakarta Erlangga.

Sukardi, (2017). Metodologi Penelitian Pendidikan, Kompetensi dan Praktiknya. Yogyakarta: Bumi Aksara.

Soetjiningsih, Ramuh, Suraatmaja, Rusmil, Pangkahila, Fadlyana, dkk., 2004. Buku Ajar Tumbuh Kembang Remaja dan Permasalahannya. Jakarta: Sagung Seto.

Yusuf, A. M. (2011). Metodologi Penelitian, Padang: UNP Press.

Yusuf, Y., Rina, K. \& Septi, R. (2014). Hubungan Pengetahuan Menarche dengan Kesiapan Remaja Putri Menghadapi Menarche di SMP Negeri 3 Tidore Kepulauan. Jurnal Keperawatan, 2 (2). 